\title{
Eastern Jilin Province Rice Cold Damage Risk Vulnerability Curve Established Based on CERES-Rice Model
}

\author{
Chunming Guo ${ }^{1}$, Meng $\mathrm{Zhu}^{2}$, Tiehua $\mathrm{Cao}^{3}$, Jiquan Zhang ${ }^{2 *}$ \\ 1 Jilin Meteorological Bureau, Changchun, 130024, China \\ 2 Northeast Normal University College of Environmental Science, Changchun, 130024, China \\ 3 Jilin Academy of Agricultural Sciences, Changchun, 130024, China
}

\section{基于 CERES-Rice 模型的吉林省东部水稻冷害风险脆 弱性曲线建立

\author{
郭春明 ${ }^{1}$, 朱萌 ${ }^{2}$, 曹铁华 ${ }^{3}$, 张继权 ${ }^{2 *}$ \\ 1 吉林省气象局, 长春 130024 中国 \\ 3 吉林省农业科学院, 长春 130024 中国
} \\ 2 东北师范大学环境科学学院, 长春 130024 中国}

\begin{abstract}
Eastern Jilin Province is one of the most frequent areas of rice chilling injury, vulnerability is used to reflect the possibility of hazard bearing body by stress factors Stress loss is the key factor in the formation of disaster risk, disaster risk is connected with the disaster bridge, the paper's natural vulnerability of rice to start the application CERES-Rice model daily by the growth of rice simulation grid, select a typical case of cold damage and the average years of meteorological data as input to the model, excluding the impact of water stress calculation key physiological parameters loss rate of different rice growth stages due to the cold damage caused by the final fitting-based CERES-Rice model different rice growth stages vulnerability curve, booting - heading in rice cold damage the most sensitive, followed by the heading stage - maturity, sensitivity is the weakest of transplanting - booting stage. Fragility curve established to provide early warning of threatened rice chilling injury occurs, estimates varying degrees of
\end{abstract}

cold damage may cause loss of crop production, achieve rice chilling injury risk in real-time warning.

Keywords: rice; cold damage; vulnerability curve; Eastern Jilin Province

\section{摘要}

吉林省东部是我国水稻冷害发生最频繁的地 区之一 ${ }^{[1]}$, 脆弱性是用来反映承灾体受到胁迫因子 胁迫造成损失的可能性, 是影响灾害风险形成的关 键因子, 是连接灾害风险与灾情的桥梁, 本文从水 稻的自然脆弱性入手, 应用 CERES-Rice 模型逐日 逐网格模拟水稻的生长过程, 选取冷害的典型案例 年与多年气象数据平均值作为模型的输入, 排除水 分胁迫的影响, 计算出水稻不同生育期由于冷害造 成的关键生理指标损失率, 最终拟合出基于 CERES-Rice 模型水稻不同生育期的脆弱性曲线, 孕穗期-抽穗开花期水稻冷害最敏感, 其次是抽穗开 花期-成熟期, 敏感性最弱的是移栽期-孕穗期。脆 弱性曲线的建立为水稻冷害的发生提供先兆预警,

* 通讯作者: 张继权 $(1965$ - ), 男, 吉林九台人, 教授, 博士生导师, 主要从事综合灾害与生态环境风险评价、预警与应急管理等方面研究. E-m ail: zhangjq022@nenu.edu.cn 
Risk Analysis and Crisis Response in Big Data Era (RAC-16)

估算不同冷害程度可能造成作物产量的损失, 实现 了水稻冷害风险预警的实时化。

\section{1.引言}

水稻是我国最重要的口粮作物之一, 东北地区 是水稻冷害发生最频繁的地区, 水稻生产安全直接 关系到我国粮食生产安全。脆弱性是自然灾害风险 形成理论的重要组成部分, 它可以用来评估承灾体 遭受损害的程度, 当承灾体的脆弱性侧重于因灾造 成的灾情损失时, 我们通常采用致灾 (h) 与成害(d) 之间的关系曲线或方程式来表示, 把这样的曲线叫 做脆弱性曲线或者称其为灾损率曲线, 我们用脆弱 性曲线来表征某种灾害类型的致灾强度与其相对 应的损失率的关系 ${ }^{[2-4]}$ 。本文研究的承灾体为水稻, 水稻不同生育期冷害的脆弱性是指水稻遭受低温 这一不利的气象因子所造成的水稻不同生育期各 生理指标的损失。从水稻的自然脆弱性出发, 依据 野外实验数据和 CERES-Rice 模型建立了水稻不同 生育期的脆弱性曲线, 可以为吉林省东部水稻不同 生育期冷害风险提供预警和预报，使得农民可以快
关键词: 水稻; 冷害; 脆弱性曲线; 吉林省东部

速对不同生育阶段水稻冷害采取防灾减灾措施，减 少因冷害发生对农民造成的经济损失, 并为政府部 门制定防灾减灾政策提供科学依据。

\section{2.资料与方法}

\section{1 研究区概况}

吉林省东部地区经纬度范围大致在 $41^{\circ} \sim 45^{\circ} \mathrm{N}$, $124.5^{\circ} \sim 131^{\circ} \mathrm{E}$ 之间。吉林省东部主要位于长白山区, 有海拔较高的山峰、山地, 也存在着少量河流谷地, 海拔高度大致在 2 2667 $\mathrm{m}$ 之间, 地形主要是东南 部长白山区海拔高度较高, 吉林省东部地区总面积 约为 7.58 万 $\mathrm{km}^{2}, 2013$ 年统计的水田面积是 $8864.13 \mathrm{~km}^{2}$ 。行政区上包括 3 个地级市, 分别为通 化市、白山市、延边朝鲜族自治州。本文研究选取 了吉林省东部的 10 个气象站点（图 1)。

\section{2 资料来源}

选取了吉林东部 10 个气象站点的实测资料。 研究所用的资料有：1）1961 2010 年日最高温度、 日最低温度、日平均温度、降水量、日照时数 (来 自国家气象信息中心资料室)；2）2000 2014 年水 稻发育期资料（吉林省农科院）；3）1961 2014 年 水稻低温冷害灾情资料（来自《中国气象灾害大典 (吉林卷)》、吉林省统计年鉴)。

\subsection{CERES-Rice 模型}

(1) 发育期模型

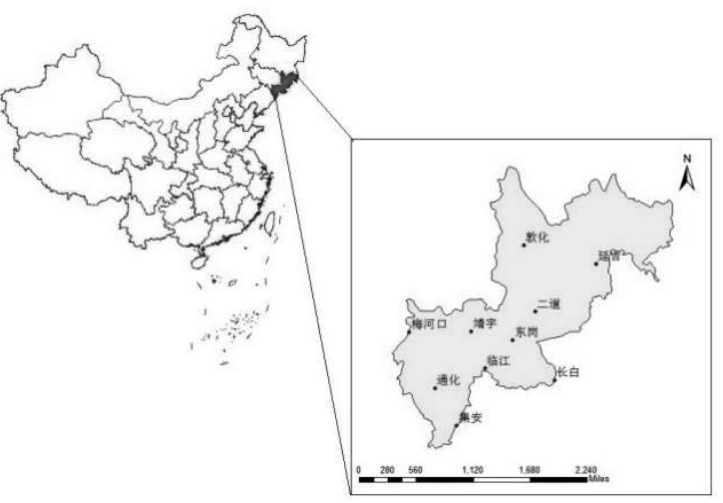

图 1. 研究区概况

CERES-Rice 模型假设发育速度与在 $8^{\circ} \mathrm{C} \sim 32^{\circ} \mathrm{C}$ 之间的平均温度成比例。它提出: 热时 (Thermal Time）的概念。每日热时（DDT）的计算式为：

$$
D D T=\frac{T M A X+T M I N}{2}-8
$$

不同发育期需要不同的 DDT。光敏感品种在 光敏感阶段当日长大于临界值时, 需要 DDT 较多。 发育期的几个参数 $\mathrm{P}_{1}$ : 基本营养生长期的 DDT; $\mathrm{P}_{2} \mathrm{O}$ : 临界光周期最长的一天; $\mathrm{P}_{2} \mathrm{R}$ : 日长反应系数, 由不同日照时长的试验求得。 
Risk Analysis and Crisis Response in Big Data Era (RAC-16)

(2) 物质生产模型

CERES-Rice 模型对生物干重的生产采用的是 一种简单的计算方法, 即由光能直接转换的方法, 建立了每日光合同化量与光合有效辐射 (PAR) 的 指数函数关系。计算潜在干物质生产量的公式为: $C A R B O=P C A R B \times P R F T \times M I N(S W D F 1, N D E F 1)(2$

式中, PCARB 为潜在干物质生产量 $\mathrm{g} / \mathrm{m}^{2}, \mathrm{~d}$; $P A R$ 为光合有效辐射, $M J / m^{2}, d ; G_{1}$ 为 PAR 转换为 干物质的系数, $g / M J$; 实际干物质生产的计算公式 为:

$P L A G M S=7.5 \times C U M P H^{0.5} \times T I$

式中, $\mathrm{PRFT}=0 \sim 1$, 温度因子, 最适温度为 $26^{\circ} \mathrm{C}$, $\mathrm{SWDF} 1=0 \sim 1$, 水分因子, $\mathrm{NDEF} 1=0 \sim 1$, 氮素因子。

(3) 叶的生长及衰老模型

模型分阶段对叶面积进行了模拟。在初始条件 下, 叶出现速率是温度的线性函数, 温度范围为 $0 \sim 26^{\circ} \mathrm{C}$ 。假设叶出现速率和叶面积增长速率都由温 度条件来控制, 叶面积增长速率就能够表达为与温

\section{3.结果与分析}

\section{1 模型参数校验}

CERES-Rice 模拟是以逐日的气象数据 (日最 高气温、日最低气温、降雨量、太阳辐射量）为输 入数据, 土壤属性数据主要包含土壤水分数据、土 壤酸碱度、土壤养分数据为输入, 田间管理数据 (水 稻的移栽日期、移栽的深度、每公顷移栽的水稻的 苗数, 施肥日期、种类与数量, 灌溉日期与水量) 作为模型的输入值 (如图 2 所示)。运行模型时, 确定作物的遗传参数非常重要, 它直接影响到模型
度相关的线性函数, 将叶出现速率与扩展速率综合 考虑, 则主茎叶面积增长速率是:

PLAGMS $=7.5 \times C U M P H^{0.5} \times T I$

式中 PLAGMS 为主茎叶面积增长速率 $\left(\mathrm{cm}^{2} / \mathrm{d}\right), \mathrm{CUMPH}$ 为叶间隔数, TI 为日出叶积温 间隔数。

（4）籽粒产量模型

CERES-Rice 模型假设水稻千粒重是稳定的, 是品种参数。䊏粒产量与穗重成正比, 而穗重由干 物质生产量与穗数决定的, 模型认为每株粒数是茎 部干重 (stem weight, STMWT) 的线性函数, 而 单位面积籽粒数 (grain number per unit ground area, GNA）是每株粒数（grain number per plant, GNP) 与密度 (D) 的乘积, 公式如下 ${ }^{[5-6]}$ :

$$
G N P=S T M W T \times G_{1}
$$$$
G N A=G N P \times D
$$

的模拟效果, 必须对模型的参数进行本地化校验。 吉林省东部地区种植的水稻品种主要有通化地区 普遍种植的吉粳 88 , 白山地区普遍种植的长白 9 , 以及延吉地区普遍种植的吉粳 83 。下面分别对这三 种水稻品种进行遗传参数的率定。模型输入 2007 2014 年这 8 年的通化、长白、延吉试验站点 的气象数据、土壤数据以及田间管理数据, 将模型 输出的水稻产量与在试验站点的实际水稻产量进 行拟合。通过反复运行模型, 运用模型中的遗传算 法调整模型的不同地区不同水稻品种的遗传参数, 直到模拟值与实测值的误差最小, 而且整体变化趋 势比较一致为止 ${ }^{[7-8]}$ (如图 3 所示)。

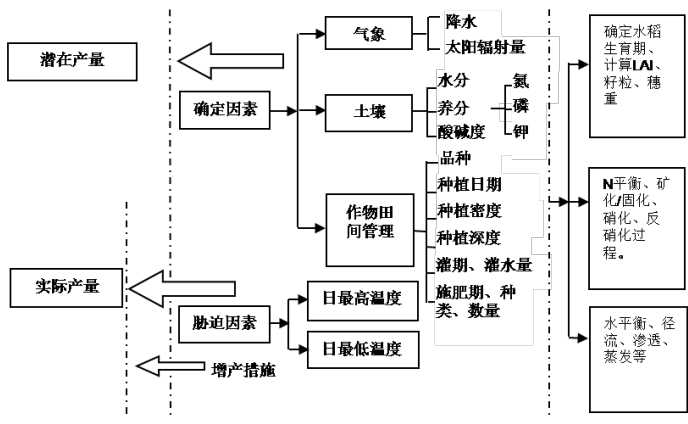

图 2. CERES-Rice 模型模拟过程及作物产量计算 
Risk Analysis and Crisis Response in Big Data Era (RAC-16)
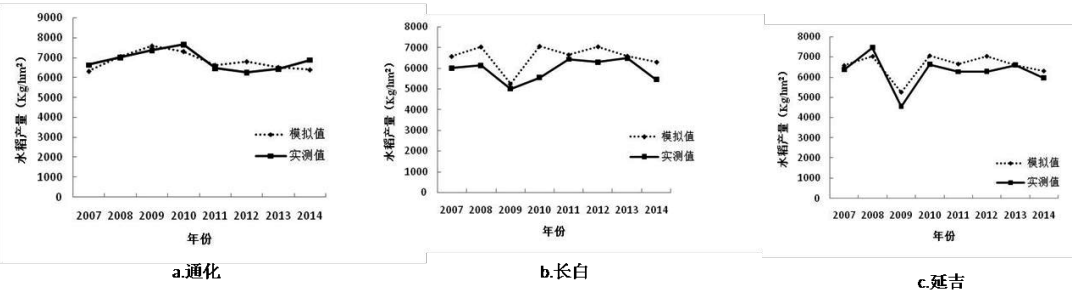

图 3. 模型参数校验

通过计算通化、长白、延吉模型水稻品种遗传 参数检验的结果为平均绝对误差分别是 $4.05 \%$ 、 $9.78 \% 、 7.04 \%$; 相对均方根误差分别为 $4.76 \%$ 、 $10.83 \% 、 7.61 \%$ 。说明模型的模拟精度较好。

\section{2 基于 CERES-Rice 模型水稻冷害脆弱性曲线构}

建

将 CERES-Rice 模型进行了空间格网化运行, 参考以往历史灾情数据选取了 1972 年、1980 年、 2009 年三个不同程度的冷害案历年的相关数据输 入到模型中, 排除水分胁迫对模拟结果的影响。通 过模型模拟研究区内 $8 \mathrm{~km} \times 8 \mathrm{~km}$ 网格单元内水稻的 生长过程。运用活动积温的距平值和日冷积温值分 别作为营养生长阶段和生殖生长阶段冷害的致灾 强度影响因子。我们通过 GIS 的空间插值功能, 分 别计算不同案历年的每个格网的模型输入的相关 数据值, 最终计算冷害致灾强度值。其计算公式如 下: 成熟期）

营养生长阶段（移栽期-孕穗期、抽穗开花期-

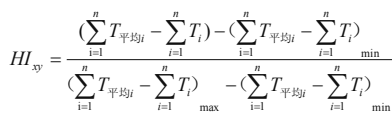

生殖生长阶段 (孕穗期-抽穗开花期):

$H I_{x y}=\frac{\sum_{i=1}^{n}\left(T_{0}-T_{i}\right)-\left[\sum_{i=1}^{n}\left(T_{0}-T_{i}\right)\right]_{\min }}{\left[\sum_{i=1}^{n}\left(T_{0}-T_{i}\right)\right]_{\max }-\left[\sum_{i=1}^{n}\left(T_{0}-T_{i}\right)\right]_{\min }}$

其中, $\mathrm{HI}_{\mathrm{xy}}$ 为 $\mathrm{x}$ 年第 $\mathrm{y}$ 网格的冷害致灾强度值。 $\mathrm{T}$ 平均 $\mathrm{i}$ 为第 $i$ 日的多年平均气温, $\mathrm{T}_{\mathrm{i}}$ 为第 $i$ 日的气温 值, $\mathrm{T}_{0}$ 为水稻生殖生长阶段的水稻的临界温度 (㝋 穗期 $19.5^{\circ} \mathrm{C}$; 抽穗开花期 $20.5^{\circ} \mathrm{C}$ ); $i$ 为某生长发育 阶段的天数。模型运行的时候, 温度是影响水稻生 理产量的主要胁迫因素, 设定: 多年平均的气温状 况为 (A1 情景), 案历年的气温状况为 (A2 情景),
分别对其进行逐网格的模拟。即 $\mathrm{A} 1$ 情景与 $\mathrm{A} 2$ 情 景的相应生理指标的差值即为受温度胁迫影响的 损失程度。损失率的计算公式如下:

$$
S_{x y}=\frac{Y_{1}-Y_{2}}{Y_{1}} \times 100 \%
$$

式中, $S x y$ 为 $\mathrm{x}$ 年第 $\mathrm{y}$ 网格的某生育期的某指 标的冷害损失程度; $\mathrm{Y} 1$ 和 $\mathrm{Y} 2$ 分别为 $\mathrm{A} 1$ 和 $\mathrm{A} 2$ 情 景下的某一指标的数值。

关于生理指标的选择, 移栽期到孕穗期主要影 响的是水稻的叶面积指数, 所以把叶面积指数作为 该阶段的评估指标; 孕穗期到抽穗开花期选择籽粒 数作为评估指标; 抽穗开花期到成熟期, 选择穗重 损失率作为生理损失评估指标, 模型模拟的穗重是 由干物质生产量、穗数、粒重共同计算的结果。由 此模拟出不同冷害强度下不同生育期对最终产量 起主要影响的关键生理指标的损失率, 并且拟合出 水稻的自然脆弱性曲线 (图 4 所示), 每个生育期 都通过了 $\alpha=0.05$ 的 $\mathrm{F}$ 检验, 各个生育期的 $\mathrm{R}^{2}$ 值分 别为 $0.503 、 0.802$ 和 0.643 。整体上看, 各个生育 期随着冷害致灾强度的增大, 相应指标的损失率都 呈现上升的趋势, 水稻移栽期-㝋穗期叶面积指数呈 现线性上升的趋势, 孕穗期-抽穗开花期䊏粒损失率 呈现指数上升趋势。且在致灾强度为 0.6 时, 损失 率有迅速的上升。而且可以看出孕穗期-抽穗开花期 损失率最大, 说明这一时期对冷害最敏感, 脆弱性 最大。抽穗开花期-成熟期, 穗重的损失率呈指数上 升的趋势, 这一时期的冷害会影响干物重和粒重, 所以选择穗重这一指标有其合理性。从图中可以看 出, 冷害致灾强度在 0.6 时, 穗重的损失率有明显 的升高, 这一阶段对冷害也比较敏感, 脆弱性比较 大。所以人们常说夏季低温对水稻的影响最大, 特 别是 7 月中下旬到 8 月中下旬, 这时期的低温会对 水稻造成巨大的损失, 穗粒数减少, 颗粒不饱满。 
Risk Analysis and Crisis Response in Big Data Era (RAC-16)

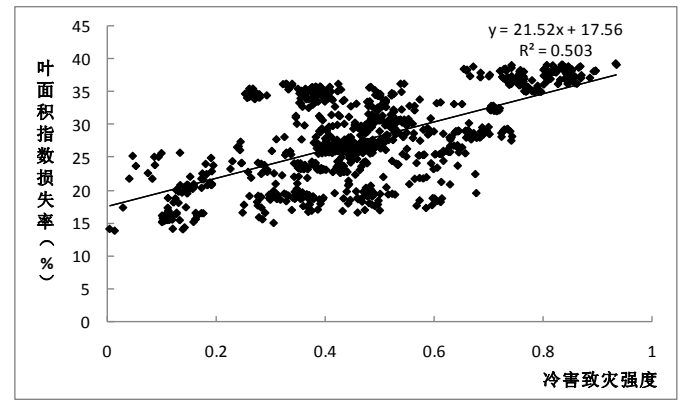

a.移栽期-孕穗期

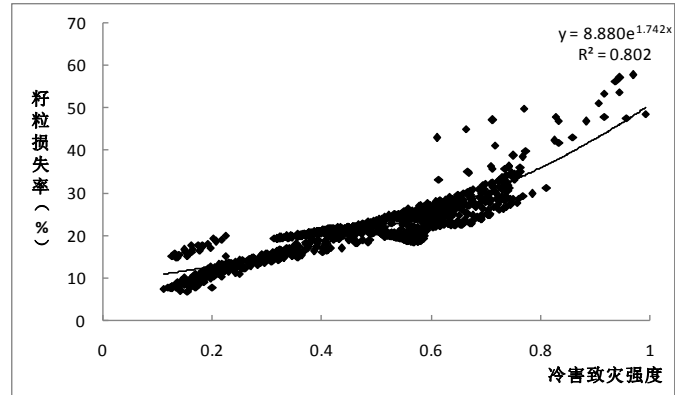

b. 孕穗期-抽穗开花期

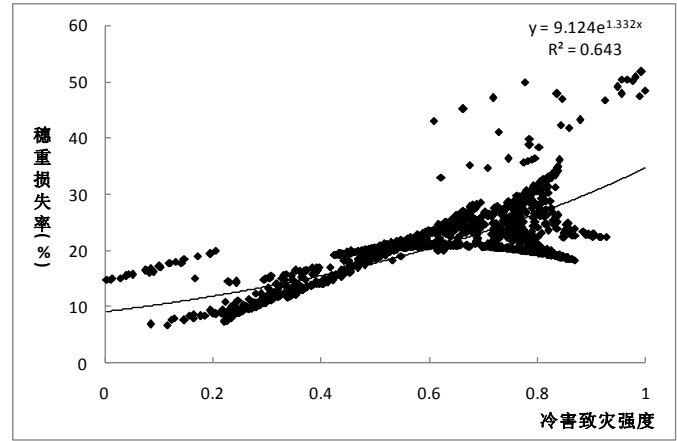

c. 抽穗开花期-成熟期

图 4. 不同生育期水稻脆弱性曲线（a-c）

\section{3 脆弱性曲线检验}

根据模型模拟得出水稻不同生育期的脆弱性 曲线分别为 $\mathrm{y}_{1} 、 \mathrm{y}_{2} 、 \mathrm{y}_{3}$ :

$\left\{y_{1}=21.52 x+17.56,\left(R^{2}=0.503, r=0.635, p<0.05\right)\right.$

$\left\{y_{2}=8.880 e^{1.742 x},\left(R^{2}=0.802, r=0.880, p<0.05\right)\right.$

$y_{3}=9.124 e^{1.332 x},\left(R^{2}=0.802, r=0.880, p<0.05\right)$
计算每个格网内两种情景下最终产量与各个 生育期相应生理指标的脆弱性进行相关分析, 移栽 期-孕穗期、孕穗期-抽穗开花期、抽穗开花期-成熟 期, 相关系数分别为 $0.426 、 0.624 、 0.501, \mathrm{P}<0.05$, 达到显著性水平。 
Risk Analysis and Crisis Response in Big Data Era (RAC-16)

\section{4. 结论与讨论}

吉林省东部地区水稻各个生育期随着冷害致 灾强度的增大, 相应指标的损失率增加, 水稻移栽 期-孕穗期冷害致灾强度与叶面积指数损失率呈线 性上升的趋势, 其他生育期呈指数上升趋势且在致 灾强度为 0.6 时, 损失率有迅速的上升。而且可以 看出孕穗期-抽穗开花期损失率最大, 其次是抽穗开 花期-成熟期, 最后是移栽期-孕穗期, 因此可以得 出孕穗期-抽穗开花期冷害的敏感性最强, 其次是抽 穗开花期-成熟期, 敏感性最弱的是移栽期-孕穗期。 在以后的研究中模型参数进行调整的时候要尽量 选择更加多的方法和指标, 虽然产量作为模型调整 参数的指标精确度较高, 但是选择多个调整参数指 标更加的准确, 而且以往研究中有 GLUE、PEST 还有传统的试错法分别对模型进行调参，我们在实 际研究中应该选取适合自己研究问题的调整参数 的方式, 使得模型模拟的结果更加的精确 ${ }^{[9]}$ 。

\section{Acknowledgements}

This study was supported by "Twelfth five-year" science and technology support project (2011BAD32B00-04) and National Natural Science Foundation (41571491) and the National Non-Profit Research Program of China (No.201401015).

\section{致谢}

本研究得到了国家 “十二五” 科技支撑项目 (2011BAD32B04)、国家自然科学基金项目
(41571491) 和水利部公益性行业科研专项经费项 目 (201401015) 的支持。

\section{参考文献:}

[1]中国气象灾害大典编委会.中国气象灾害大典吉 林卷.北京: 气象出版社, 2008 .

[2]董姝娜, 庞泽源, 张继权, 等.基于 CERES-Maize 模型的吉林西部玉米干旱脆弱性曲线研究. 灾害 学, 2014(3):115-119.

[3] 庞泽源. 基于 CERES-Maize 模型的吉林西部玉米 干旱脆弱性评价与区化研究: [硕士学位论文]. 东北师范大学, 2014.

[4]于汐, 唐彦东, 王慧彦. 基于灾害背景下脆弱性 基本内涵研究.中国灾害防御协会风险分析专业 委员会第四届年会论文集，2010.

[5]刘铁梅, 谢国生.农业系统分析与模拟. 北京: 科 学出版社, 2010, 158-162.

[6]高亮之. 农业模型学基础.香港: 天马图书有限公 司, 2004, 137-138.

[7]宋利兵, 陈上, 姚宁, 等. 基于 GLUE 和 PEST 的 CERES-Maize 模型调参与验证研究.农业机械 学报, 2015,46(11): 95-111.

[8]庞泽源, 董姝娜, 张继权, 等.基于 CERES-Maize 模型的吉林西部玉米干旱脆弱性评价与区划.中 国生态农业学报，2014，22(6)：705-712.

[9] F. Kadri. The assessment of risk caused by fire and explosion in chemical process industry: a domino effect-based study. Journal of Risk Analysis and Crisis Response. 3(2): 66-76, 2013. 